\begin{tabular}{lccccccccc}
\hline $\begin{array}{l}\text { Diagnosis } \\
\text { MA/SD }\end{array}$ & MTX & PHT & GOL & ETA & ADA & CER & ABA & SECU Total \\
\hline $\begin{array}{l}\text { Rheumatoid arthirits } \\
\quad 32 \pm 16 \text { (3) }\end{array}$ & 30 & 0 & 2 & 4 & 2 & 1 & 2 & 0 & 41 \\
$\begin{array}{l}\text { Psoriatic arthritis } \\
\quad 52 \pm 17\end{array}$ & 9 & 0 & 5 & 1 & 1 & 1 & 0 & 1 & 18 \\
$\begin{array}{l}\text { Anquilosing spondilytis } \\
\quad 48 \pm 12\end{array}$ & 1 & 0 & 2 & 2 & 3 & 2 & 0 & 0 & 10 \\
$\begin{array}{l}\text { Osteoporosi } \\
\quad 79 \pm 7\end{array}$ & 0 & 40 & 0 & 0 & 0 & 0 & 0 & 0 & 40 \\
Total $(\%)$ & $40(37 \%)$ & $40(37 \%)$ & $9(8 \%)$ & $7(6 \%)$ & $6(6 \%)$ & $4(3 \%)$ & $2(2 \%)$ & $1(1 \%)$ & 109 \\
\hline
\end{tabular}

Total $(\%)$ $40(37 \%) 40(37 \%) 9(8 \%) 7(6 \%) 6(6 \%) 4(3 \%) 2(2 \%) 1(1 \%) \quad 109$

MTX: methotrexate PTH: teriparatide GOL: golimumab ETA: etanercept ADA: adalimumab CER: certolizumab ABA: abatacept SECU: secukimumab SD: standard deviation.

A total of 238 visits were made in Rheumatology-DHU.

Adherence to treatment was $98.2 \%$.

Six patients $(5.5 \%)$ required a new referral to Rheumatology-DHU: 1 for poor adherence to treatment (ADA), 3 for skin lesions (2 MTX and $1 \mathrm{GOL}$ ), 2 supervise the treatment (1 CER and $1 \mathrm{MTX})$.

In $9 \%$ of the patients, the education was done to a reference person and not to the patient himself.

The number of visits in the Rheumatology-DHU were: 1 in 26 patients (MS of 66 +/- 19.6 years), 2 in 59 patients (MS $65+/-18$ ); 3 in 13 patients (MS $64+/-13$ ); 4 in 6 patients (MS $67+/-14$ ); 5 in 2 patients (MS $68+/-17$ ), 6 in 2 patients (MS 70 $+/-22), 9$ in 1 patient (47 years).

We analyzed PTH and MTX groups (because they had the highest number of patients) and we observed that in the PTH group $82 \%$ required $\leq 2$ visits, $18 \%>$ of 2 visits. Patients in MTX group: $77 \% \leq 2$ visits and $23 \%>2$ education visits. There weren't significant differences between the two groups $(p=0.576)$.

Conclusions: Adherence to treatment in patients who are referred to Rheumatology-DHU to learn the self-administration of a subcutaneous drug is very high.

The new visits in Rheumatology-DHU for doubts or side effects were few.

Patients on PTH treatment, who were older, didn't require a higher number of visits or more new referrals to Rheumatology-DHU. Therefore, age is not a limiting factor for the right learning of patients.

The patient's education by nurse in Rheumatology-DHU is necessary for the right control of our patients

Disclosure of Interest: None declared

DOI: 10.1136/annrheumdis-2017-eular.3201

\section{AB1184 EDUCATIONAL NEEDS OF PATIENTS WITH RHEUMATIC DISEASES RECEIVING BIOLOGICS}

A.T. Kotulska ${ }^{1}$, E.J. Kucharz ${ }^{1}$, P. Wiland ${ }^{2}$, M. Olesinska ${ }^{3}$, A. Felis-Giemza ${ }^{3}$, M. Kopec-Medrek ${ }^{3}$, W. Romanowski ${ }^{3}$, L. Szymczak-Bartz ${ }^{3}$, M. Tlustochowicz ${ }^{3}$, J. Lewandowicz ${ }^{3}$, J. Kowalska-Majka ${ }^{3}$, J. Bucka ${ }^{3}$, M. Majdan ${ }^{3}$, Z. Kielbik ${ }^{3}$, M. Korkosz ${ }^{3}$, A. Bielinska ${ }^{3}$, P. Leszczynski ${ }^{3}$, K. Pawlak-Bus $^{3}$, M. Puszczewicz ${ }^{3}$, M. Majewski ${ }^{3}$, K. Smolik ${ }^{3}$, T. Migas-Kukla ${ }^{3}$, M. Sochocka-Bykowska ${ }^{3}$, M. Szarecka ${ }^{3}$, B. Luberda ${ }^{3}$, M. Falenta-Hitnarowicz ${ }^{3}$, J. Swikszcz-Gniadek ${ }^{3}$, W. Lepiarz-Rusek ${ }^{3}$, G. Rozwadowski ${ }^{3}$, B. Chara ${ }^{3}$, J. Zajdel $^{3}$, Z. Zdrojewski ${ }^{3}$, I. Rosmus-Kuczia ${ }^{3}$ on behalf of Research Group of the Polish Society of Rheumatology. ${ }^{1}$ Internal Medicine and Rheumatology, Medical University of Silesia, Katowice; ${ }^{2}$ Rheumatology and Internal Medicine, Medical University of Wroclaw, Wroclaw; ${ }^{3}$ Research Group of the Polish Society of Rheumatology, Katowice, Poland

Background: Biologics are still considered by patients as a new and partially enigmatic tool for management of rheumatic diseases.

Objectives: The study was designed to evaluate educational needs and sources of knowledge in patients with rheumatic diseases treated with biologics.

Methods: Anonymous questionnaires were distributed in 23 Polish rheumatological centers involved in the treatment, 1231 questionnaires were used for analysis. Responses were received from 606 patients with rheumatoid arthritis, 427 with ankylosing spondylitis, 117 psoriatic arthritis, and 62 adult patients with juvenile idiopathic arthritis (in whom administration of the drugs had been introduced before they were 18-year-old), as well as 19 ones receiving the drugs due to other musculoskeletal disorders. The investigated group constituted about one-fifth of all rheumatic patients on biologics in Poland.

Results: Almost all the patients had learnt for the first time on biologics from their rheumatologist $(93 \%)$. Few only patients had got such data from internet or from other patients. Likewise, most of the patients got majority of educational data on treatment with biologics from rheumatologist who was supervising the therapy $(82 \%)$. Remaining sources included internet $(8 \%)$ and other patients $(5 \%)$. Relative low number of patients was educated by nurses $(2 \%)$. Most of the patients $(87 \%)$ were looking for more details on biological treatment. The patients with rheumatic disease lasting less than $10 \mathrm{yrs}$. were more interested in the management than those suffering longer. Most of the patients (94\%) considered their rheumatologist as the main person responsible for their education on biologics. There was no difference between patients with various rheumatic diseases as well as no difference was found between female and male patients. Biological treatment attracted more interest in younger than older patients.

Conclusions: Education is still a challenge in patients receiving biologics. Most of the patients represented traditional attitude to health education, expecting almost all educational data to be provided by their physician. We were surprised that role of the nurses was found to be rather low. An increase in role of nurses seems to be the future aim of the educational efforts in Polish rheumatology.

Disclosure of Interest: None declared

DOI: 10.1136/annrheumdis-2017-eular.2999

\section{AB1185 REAL-LIFE EXPERIENCE AND MUTUAL EXPECTATIONS OF PATIENTS AFFECTED WITH CHRONICAL INFLAMMATORY RHEUMATIC DISEASES AND THEIR RELATIVES; CONSEQUENCES IN PATIENT EDUCATION: A QUALITATIVE STUDY BY THE PROXYRIC GROUP OF THE PATIENT EDUCATION DIVISION OF FRENCH RHEUMATIC DISEASE SOCIETY}

D. Poivret ${ }^{1}$, A. Untas ${ }^{2}$, E. Boujut ${ }^{3}$, C. Vioulac ${ }^{2}$, C. Delannoy ${ }^{4}$, L. Carton ${ }^{5}$, N. Legoupil ${ }^{6}$, G. Hayem ${ }^{7}$, S. Pouplin ${ }^{8}$, A.-C. Rat ${ }^{9}$, J.-S. Giraudet-Le Quintrec ${ }^{6}$ C. Beauvais ${ }^{10}$. ${ }^{1}$ Chr Metz Thionville, Metz; ${ }^{2}$ Institut psychologie Paris Descartes, Paris: ${ }^{3}$ Institut psychopathologie et processus de santé, Versailles: ${ }^{4}$ Cabinet Psychologie; ${ }^{5}$ AFLAR; ${ }^{6}$ Service Rhumatologie A, hôpital Cochin, Paris; ${ }^{7}$ Service Rhumatologie, Hôpital Ambroise Paré, Boulogne Billancourt; ${ }^{8}$ Service Rhumatologie, CHU, Rouen; ${ }^{9}$ Service Rhumatologie, CHU Brabois, Nancy; ${ }^{10}$ Service Rhumatologie, CHU Saint Antoine, Paris, France

Background: Interaction with relatives has a significant role on patients' health, and can also impair relatives'health. Education processes need codification to enrole relatives in the programms.

Objectives: To create a patient education program for relatives and patient affected by rheumatic inflammatory desease

Methods: Individual semi-directed by 2 psychologists interviews, have been performed and their thematic content analysed with the QDA Miner program. A guide had been achieved by rheumatologists, psychologists et patient association representatives. The (patient/relative) dyad, has been first questioned together, and then individually.

Results: 20 patients, average age 59 years (27-79) affected with Rheumatoïd Arhritis $(n=13)$, Spondyloarthritis $(n=9)$ with an average disease duration of 12,8 years (1-39) and one of their relatives (being their spouse in 18 cases) have been recruited in 7 rheumatology departments in France. Common life duration was 27,5 years as an average $(1,5-57)$. About $2 / 3$ of patients and relatives have a common view on: relative's role in bringing an emotional support but needs a knowledge on disease and treatments; emotional distress experienced by both patient and relative; the worrries and reative's feelings of not knowing how to to do; the help brought by the relative in everyday's life and his participation to care management. Only a few relatives talked about concerns, regrets of past life, and burden feeling of patient. Relatives also express unfairness feelings. $2 / 3$ of patients and relatives report will of independence of the patient, who wants to manage alone, and does not express his difficulties. $50 \%$ of relatives think they anticipate patient's needs, they are also directly resquested by the patients. On the other side, the patients often report that they watch over relative's health. $50 \%$ of patients and relatives mention the idea of complementarity and "team ", but also tensions or conflicts. Patient Education contribution would be sharing and exchanging between them, according to $2 / 3$ of patients and relatives, who therefore would prefer group education (12/20). Relatives however more often mention a common education with patient, and patients prefer a separate education of relative. The main limit to of this study is that participation to study has favored harmoniously functioning dyads, what may explain the weak rate of abandonment feeling

Conclusions: Expectations on relatives' role seem to be common in terms of practical and emotional support. Relatives sometimes mention the "positivation" of their role, but also emotional distress and helplessness feeling. Patients fear they are a burden and want to be independent. A specific educational management of relatives is more often suggested by patients than by relatives.

Disclosure of Interest: None declared

DOI: 10.1136/annrheumdis-2017-eular.1682

\section{AB1186 OPTIMISATION OF RHEUMATOLOGY UNDERGRADUATE TEACHING: SELF-DIRECTED DEVELOPMENT OF POWERPOINT PRESENTATIONS BASED ON THEORETICAL CLINICAL CASES}

F.A.H. Cooles ${ }^{1,2}$, R.L. Batten ${ }^{1}$, J. Stewart ${ }^{1}$, D. Coady ${ }^{1} .{ }^{1}$ City Hospitals Sunderland NHS Foundation Trust, Sunderland; ${ }^{2}$ NIHR Newcastle Biomedical Research Centre based at Newcastle upon Tyne Hospitals NHS Foundation Trust and Newcastle University, Newcastle Upon Tyne, United Kingdom

Background: One element of rheumatology undergraduate teaching in City Hospital Sunderland, UK traditionally involves "paper cases" delivered via small group learning and discussion. Although popular it has had poor feedback from both the students and the tutors at times especially when the tutor to student ratio is high ( $>1: 6)$. With limited numbers of tutors (Consultant Rheumatologists), this issue was becoming more frequent.

Objectives: We wished to explore alternative yet still interactive methods to highlight key learning points relating to common rheumatological conditions in a 60 minute teaching session and to make this fun and engaging. 